\title{
Investigation of morphology of recycled PET by modulated DSC
}

\author{
Bela Molnar ${ }^{1, a}$, Ferenc Ronkay ${ }^{1, b^{*}}$ \\ ${ }^{1}$ Department of Polymer Engineering, Faculty of Mechanical Engineering, Budapest University of \\ Technology and Economics, H-1111 Budapest, Müegyetem rkp. 3, Hungary \\ amolnarb@pt.bme.hu, bronkay@pt.bme.hu
}

Keywords: PET, recycling, morphology, modulated DSC.

\begin{abstract}
During research injection molded samples were made from recycled poly(ethylene terephthalate) (PET). Morphological properties of samples were investigated by modulated differential scanning calorimetry (MDSC). Total heat flow was separated in two parts, reversing and non-reversing heat flow during measurements. Relationships were found between crystallization and melting processes: the initial crystallinity equals to the non-reversing melting, and the postcrystallization processes equals to reversing melting.
\end{abstract}

\section{Introduction}

Considering its application, PET is classified as commercial plastic. Its main application area is packaging (of mineral water and soft drinks) besides fiber production. Most products are used only once and have a short life cycle. Nowadays, due to increasing usage and the stricter and stricter environmental regulations recycled PET (RPET) as a secondary raw material is available in large amount. The main application field of RPET is textile industry, while usage as a packaging material either purely or as a component of a mixture is also more and more significant [1]. There are lots of researches for different applications of recycled PET beside the fiber and packaging industry (blends, composites, building industry). An important application can be the injection molded mechanical parts, because of the amount of PET waste, and good mechanical properties of PET. Several investigations have been carried out in this field [2,3], but there are still less known and less explained phenomena and based on their deeper understanding, application areas of recycled PET can be extended.

In case of recycled PET processing, morphological structure formed in the product is essential since it determines the mechanical properties. This structure can be examined using several methods, and one of them is modulated differential scanning calorimetry (MDSC). MDSC is very similar to the conventional DSC method, but the constant rate of increase (or decrease) of temperature, is modulated (e.g.: sinusoidal, sawtooth) of a certain amplitude or frequency. The effect is to introduce simultaneously to the experiment two different time scales: a long time scale corresponding to the underlying heating rate, and the shorter time scale corresponding to the period of the modulation. The total heat flow measured with MDSC has two parts. The reversing heat flow, which is the heat capacity component, and the non-reversing heat flow, which is the kinetic component of the total heat flow. The non-reversing heat-flow is determined by deconvolution procedure. Total heat flow is a measured component, the reversing heat flow is determined by the heat capacity and the heating rate, and the non-reversing heat flow is the difference between the mentioned two components $[4,5]$.

MDSC has many advantages compared to conventional DSC. Temperature modulation provides more complex information about temperature dependent processes (e.g. melting, crystallization). Different transitions appear in different signals. Heat capacity, glass transition and most melting processes appear in reversing heat flow signal, crystallization, enthalpic recovery, decomposition and some melting appear in non-reversing heat flow signal. If there are overlapped transitions (e.g. Glass transition of the first component and crystallization of the second component at the same temperature range in a blend), two transitions can be investigated by separating them to the reversing and non- 
reversing heat flow signals [5]. There are numerous papers in which MDSC investigation of PET is described. Wunderlich [6] describes in detail the reversible melting of PET (and other semicrystalline polymers). MDSC is often used to investigate the rigid amorphous fraction in case of PET. Righetti and Androsch [7] used MDSC results to determine the change the crystallinity of their samples in function of temperature (during heating samples). The reversing specific heat capacity corresponds to the baseline specific heat capacity, i.e. the specific heat capacity without effects of latent heats. Chen and Cebe [8] investigated the vitrification and devitrification of rigid amorphous fraction of PET, using MDSC measurements. Androsch and Wunderlich [9] investigated the rigid amorphous fraction in cold-crystallized and subsequently annealed PET. Based on the reversing specific heat capacity signal they concluded that the remaining rigid amorphous fraction after cold-crystallization (at $117^{\circ} \mathrm{C}$ ) was still glassy up to at least $217^{\circ} \mathrm{C}$.

The aim of research was to produce injection molded samples from recycled PET with different processing parameters. The morphological properties of samples were analyzed by MDSC measurements. Different crystallization (cold-crystallization, non-reversing crystallization) and melting (reversing melting, non-reversing melting, total melting) were determined and compared from total-, reversing- and non-reversing heat flow signals.

\section{Experimental}

In this study, PET NeoPET80 with $0.79 \pm 0.01 \mathrm{dl} / \mathrm{g}$ intrinsic viscosity (IV), supplied by NeoGroup (Lithuania) was used. Recycled PET (RPET) with $0.59 \pm 0.01 \mathrm{dl} / \mathrm{g}$ IV was made by extrusion, modeling properties of the commercial recycled PET without any contamination.

Before the injection molding PET and RPET were dried at $160{ }^{\circ} \mathrm{C}$ for 4 hours in Hereaus UT20 hot air drying oven. The injection molded samples were made by Arburg Allrounder Advance 370S injection molding machine. Samples have 80x80 mm surface with $1 \mathrm{~mm}$ and $2 \mathrm{~mm}$ thickness. The mold temperatures were $30{ }^{\circ} \mathrm{C}$ and $60{ }^{\circ} \mathrm{C}$, the injection rates were $30 \mathrm{~cm}^{3} / \mathrm{sec}$ and $80 \mathrm{~cm}^{3} / \mathrm{sec}$. With all combinations of this setups and properties (two kinds of IV, sample thickness, mold temperature and injection rate) 16 different type of samples were injection molded.

The intrinsic viscosity of the raw material and regranulates were measured by PSL Rheotek RPV-1 solution viscosimeter at $30{ }^{\circ} \mathrm{C}$, using $60 / 40 \mathrm{wt} \%$ phenol/1,1,2,2,-tertrachloroethane as solvent.

Morphological properties were determined by modulated DSC measurements, using DSC Q2000 (TA Instruments), with $2{ }^{\circ} \mathrm{C} / \mathrm{min}$ heating rate, in $30-280{ }^{\circ} \mathrm{C}$ temperature range. Sinusoidal modulation was applied during the measurements, with $\pm 0.318^{\circ} \mathrm{C}$ amplitude and $60 \mathrm{~s}$ period. The masses of the samples were between 5-8 mg.

During DSC measurements modulated heat flow curves were registered (Fig.1), and total-, reversing- and non-reversing heat flow signals were calculated (Fig.2). This procedure is described in details elsewhere $[4,5]$. In the course of evaluation following peaks were investigated and compared: cold-crystallization $\left(\mathrm{CC}\right.$, between $\left.100-130{ }^{\circ} \mathrm{C}\right)$ and melting $\left(\mathrm{M}, 210-270{ }^{\circ} \mathrm{C}\right)$ peaks on total heat flow signal, melting (RM, 130-270 ${ }^{\circ} \mathrm{C}$ ) peak on the reversing heat flow signal, crystallization (NRC, between 130-270 ${ }^{\circ} \mathrm{C}$ ) and melting (NRM, 210-270 ${ }^{\circ} \mathrm{C}$ ) peaks on non-reversing heat flow signal (Fig. 1). Tangential sigmoid baselines were applied to determine the area of the peaks. The overlapped crystallization and melting peaks between $130-270{ }^{\circ} \mathrm{C}$ on the non-reversing heat flow signal were separated by Calisto software (Setaram, France).

The crystallinity of the crystallization/melting peaks were calculated by equation (1):

$$
C R F_{i}=\frac{\Delta h_{i}}{\Delta h^{0}} 100 \%
$$

where $\mathrm{CRF}_{\mathrm{i}}[\%]$ is the relative crystallinity of the peak where "i" can be: $\mathrm{CC}, \mathrm{M}, \mathrm{RM}, \mathrm{NRC}, \mathrm{NRM}$; $\Delta \mathrm{h}_{\mathrm{i}}[\mathrm{J} / \mathrm{g}]$ is the measured mass specific heat flow during the crystallization/melting (area of the

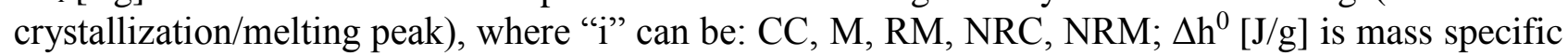
heat flow of the $100 \%$ crystalline PET $(140.1 \mathrm{~J} / \mathrm{g})$ [7]. 
The initial crystallinity of the samples were calculated by equation (2):

$$
C R F_{0}=C R F_{M}-C R F_{C C},
$$

where $\mathrm{CRF}_{0}[\%]$ is initial crystallinity of the sample, $\mathrm{CRF}_{\mathrm{M}}[\%]$ is the calculated crystallinity from melting peak on the total heat flow curve, $\mathrm{CRF}_{\mathrm{CC}}[\%]$ is the calculated crystallinity from coldcrystallization peak on the total heat flow curve.

\section{Results and discussion}

During measurements MDSC curves of 16 different samples were evaluated, and the mean values of investigated properties were analyzed and compared.

Fig. 3 shows an example of the initial crystallinity $\left(\mathrm{CRF}_{0}\right.$, difference of melting and cold crystallization peaks on the total heat flow curve) and the melting peak on the non-reversing curve $\left(\mathrm{CRF}_{\mathrm{NRM}}\right)$. In cases of 16 type produces samples, the initial crystallinity equals to the non-reversing melting:

$$
\mathrm{CRF}_{0}=\mathrm{CRF}_{\mathrm{CM}}-\mathrm{CRF}_{\mathrm{CC}}=\mathrm{CRF}_{\mathrm{NRM}}
$$

The average difference of results was $0.1 \pm 1.6 \%$ (Table 1.). Standard deviations of $\mathrm{CRF}_{0}$ and $\mathrm{CRF}_{\mathrm{NRM}}$ of samples were $0.8 \%$ and $1.3 \%$. Based on this result the melting of initial crystalline fraction of the samples can be observed on the non-reversing heat flow signal, above $230{ }^{\circ} \mathrm{C}$. Processes which appear on non-reversing signal are independent of the amplitude and frequency of the heating rate, and they are dependent on the underlying heating rate. This heating rate was applied to the sample from an initial temperature for the scan until the final required temperature was reached, and processes which are caused by the underlying heating rate have relative long occurrence time (contrary to processes in reversing heat flow signal). The initial crystallinity of the samples evolved from melt during the cooling phase of manufacturing, which result in a very ordered structure with large crystallites (compared to cold- and post-crystallization). Significant heat is necessary to melt these crystallites, this leads to the high melting temperature of the initial crystallinity, and the melting peak appearing on the non-reversing signal. The melting has no response for the modulation because there is no recrystallization in case of the initial crystallites.

Table 1. Difference between initial crystallization and non-reversing melting

\begin{tabular}{|l|r|}
\hline Melting on total heat flow curve $\left(\mathrm{CRF}_{\mathrm{M}}\right)[\%]$ & $31.8 \pm 1.7$ \\
\hline Cold-crystallization on total heat flow curve $\left(\mathrm{CRF}_{\mathrm{CC}}\right)[\%]$ & $17.6 \pm 1.0$ \\
\hline Initial crystalline fraction $\left(\mathrm{CRF}_{0}\right)[\%]$ & $14.2 \pm 0.8$ \\
\hline Non-reversing melting $\left(\mathrm{CRF}_{\mathrm{NRM}}\right)[\%]$ & $14.1 \pm 1.3$ \\
\hline Difference between $\boldsymbol{C R F}_{\mathbf{0}}$ and $\boldsymbol{C R F}_{\text {NRM }}[\%]$ & $\mathbf{0 . 1} \pm \mathbf{1 . 6}$ \\
\hline
\end{tabular}

Fig. 4 shows the cold-crystallization peak on the total heat flow curve (CC), the crystallization peak on the non-reversing heat flow curve (NRC), and the melting peak on the reversing curve (RM). The area of the two post-crystallization peaks equals to the area of the reversing melting peak:

$$
\mathrm{CRF}_{\mathrm{CC}}+\mathrm{CRF}_{\mathrm{NRC}}=\mathrm{CRF}_{\mathrm{RM}}
$$

The average difference of results was $0.0 \pm 1.3 \%$ (Table 2.). Standard deviations of post-crystalline fractions $\left(\mathrm{CRF}_{\mathrm{NRC}}+\mathrm{CRF}_{\mathrm{CC}}\right)$ and $\mathrm{CRF}_{\mathrm{RM}}$ were $4.4 \%$ and $4.8 \%$ of the samples. This process can be divide into two parts. First is the crystal perfection: at the beginning of the reversing heat flow curve (between 130 and $220^{\circ} \mathrm{C}$ ) almost equals to the non-reversing heat flow curve, hence the total heat flow curve seems to linear. During this process crystal melting and crystallization occurs simultaneously. When the secondary bonds broke between chains, the mobility of chains increase. 
This leads to a rearrangement, hence new secondary bonds and crystallites can form, or existing crystallites can grow. Second is the melting phase above $220^{\circ} \mathrm{C}$, which probably is the melting of crystallites formed during cold-crystallization. The order of the crystal structure formed during coldcrystallization probably is higher, then the order of the structure formed during post-crystallization. Crystallites are more stable, because no simultaneous melting process occur, which can cause the higher melting temperature. The melting of initial crystallinity and post crystallization processes appearing on different curves can be caused by the different crystal structures: during postcrystallization processes less perfect structure can be formed.

Table 2. Difference between post-crystallization and reversing melting

\begin{tabular}{|l|r|}
\hline Cold-crystallization on total heat flow curve $\left(\mathrm{CRF}_{\mathrm{CC}}\right)[\%]$ & $17.6 \pm 1.0$ \\
\hline Crystallization on non-reversing flow curve $\left(\mathrm{CRF}_{\mathrm{NRC}}\right)[\%]$ & $17.8 \pm 3.6$ \\
\hline Post-crystalline fraction $\left(\mathrm{CRF}_{\mathrm{NRC}}+\mathrm{CRF}_{\mathrm{CC}}\right)[\%]$ & $35.4 \pm 4.4$ \\
\hline Reversing melting $\left(\mathrm{CRF}_{\mathrm{RM}}\right)[\%]$ & $35.3 \pm 4.8$ \\
\hline Difference between $\boldsymbol{C R F}_{\boldsymbol{N R C}}+\boldsymbol{C R F}_{\boldsymbol{C C}}$ and $\boldsymbol{C R F}_{\boldsymbol{R} M}[\%]$ & $\mathbf{0 . 0} \pm \mathbf{1 . 3}$ \\
\hline
\end{tabular}

\section{Summary}

In research morphology of injection molded recycle poly(ethylene terephthalate) samples were investigated by modulated differential scanning calorimetry (MDSC). Melting and crystallization peaks on total, reversing and non-reversing heat flow signals were analyzed and compared. Relationships were found between crystallization and melting processes: the initial crystallinity equals to the non-reversing melting, and the post-crystallization processes equals to reversing melting. Crystallites formed during manufacturing, cold-crystallization and post-crystallization have different structure which cause different melting properties (e.g. reversing or non-reversing melting, different temperatures) Very small differences between results show the significance of the MDSC measurement technique in morphological analysis. In case of PET the crystallization process is very complex, it can be divided for crystallization during manufacturing, and post-crystallization (coldcrystallization and crystal perfection) processes. During these processes different crystal structures can be formed (e.g. different crystalline size, perfection of the structure). Using MDSC these processes can be separated and analyzed. The deeper analysis of crystallization processes can help to understand better the morphological properties which have a significant influence of the mechanical properties (e.g. tensile strength, impact strength) of products.

\section{Acknowledgement}

This research was realized in the framework of TÁMOP 4.2.4. A/1-11-1-2012-0001 "National Excellence Program - Elaborating and operating an inland student and researcher personal support system". The project was subsidized by the European Union and co-financed by the European Social Fund. The infrastructure of the research project was supported by the Hungarian Scientific Research Fund (OTKA K109224), and the Jász-Plasztik Kft.

\section{References}

[1] F. Welle, Twenty years of PET bottle to bottle recycling - An overview, Resour Conserv Recy. 55 (2011) 865-875.

[2] N. Torres, J.J. Robin, B. Boutevin, Study of thermal and mechanical properties of virgin and recycled poly(ethylene terephthalate) before and after injection molding, Eur Polym J. 36 (2000) 2075-2080. 
[3] J.C. Viana, N.M. Alves, J.F. Mano, Morphology and Mechanical Properties of Injection Molded Poly(Ethylene Terephthalate), Polym. Eng. Sci. 44 (2004) 2174-2184.

[4] M. Reading, D.J. Hourston, Modulated-Temperature Differential Scanning Calorimetry, Springer, Dordrecht, 2006.

[5] S.L. Simon, Temperature-modulated differential scanning calorimetry: theory and application, Thermochim Acta. 374 (2001) 55-71.

[6] B. Wunderlich, Reversible crystallization and the rigid amorphous phase in semicrystalline macromolecules, Prog. Polym. Sci. 28 (2003) 383-450.

[7] M.C. Righetti, E. Tombari, M. Angiuli, M.L. Di Lorenzo, Enthalpy-based determination of crystalline, mobile amorphous and rigid amorphous fraction in semicrystalline polymers, Thermochim Acta. 462 (2007) 15-24.

[8] H. Chen, P.Cebe, Vitrification and Devitrification of Rigid Amorphous Fraction of PET during Quasi-Isothermal Cooling and Heating, Macromolecules 42 (2009) 288-292.

[9] R. Androsch, B. Wunderlich, The link between rigid amorphous fraction and crystal perfection in cold-crystallized poly(ethylene terephthalate), Polymer 46 (2005) 12556-12566. 


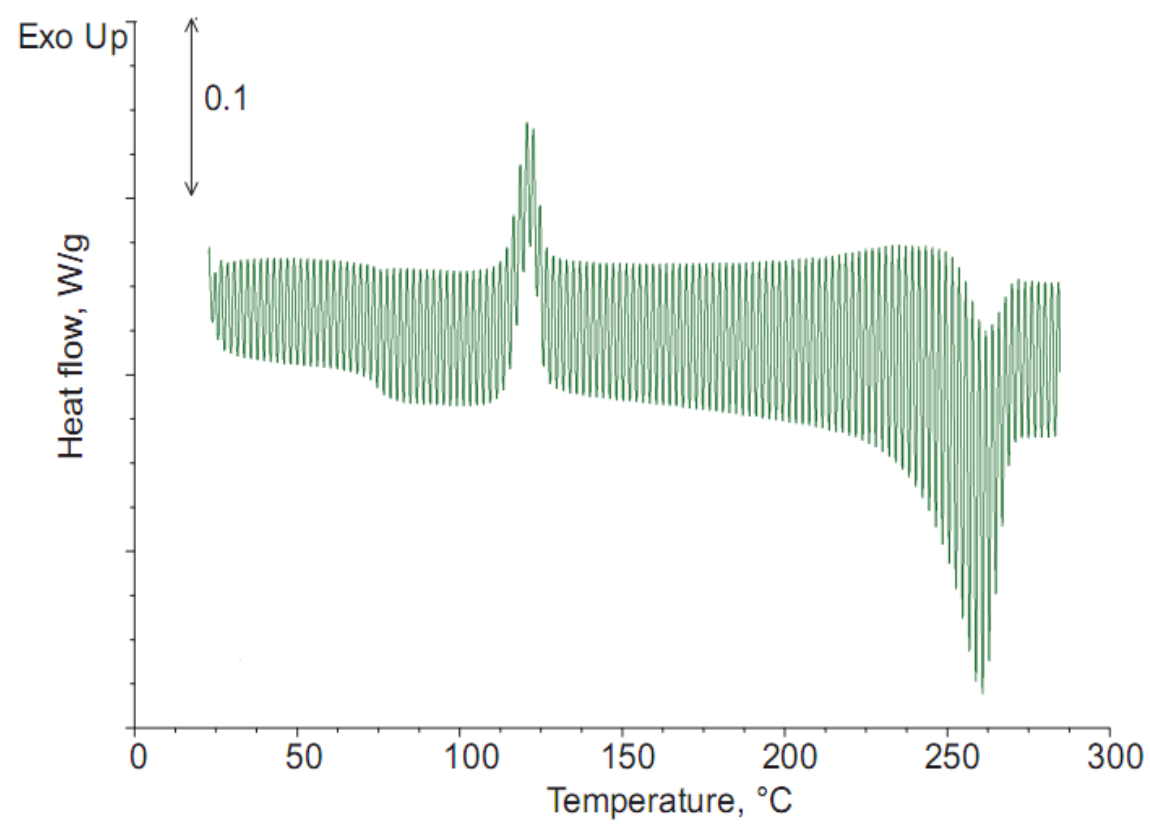

Figure 1. Measured modulated heat flow (heating rate: $2{ }^{\circ} \mathrm{C} / \mathrm{min}$, heating rate amplitude: $\pm 0,318^{\circ} \mathrm{C}$, period: $60 \mathrm{~s}$ ) 


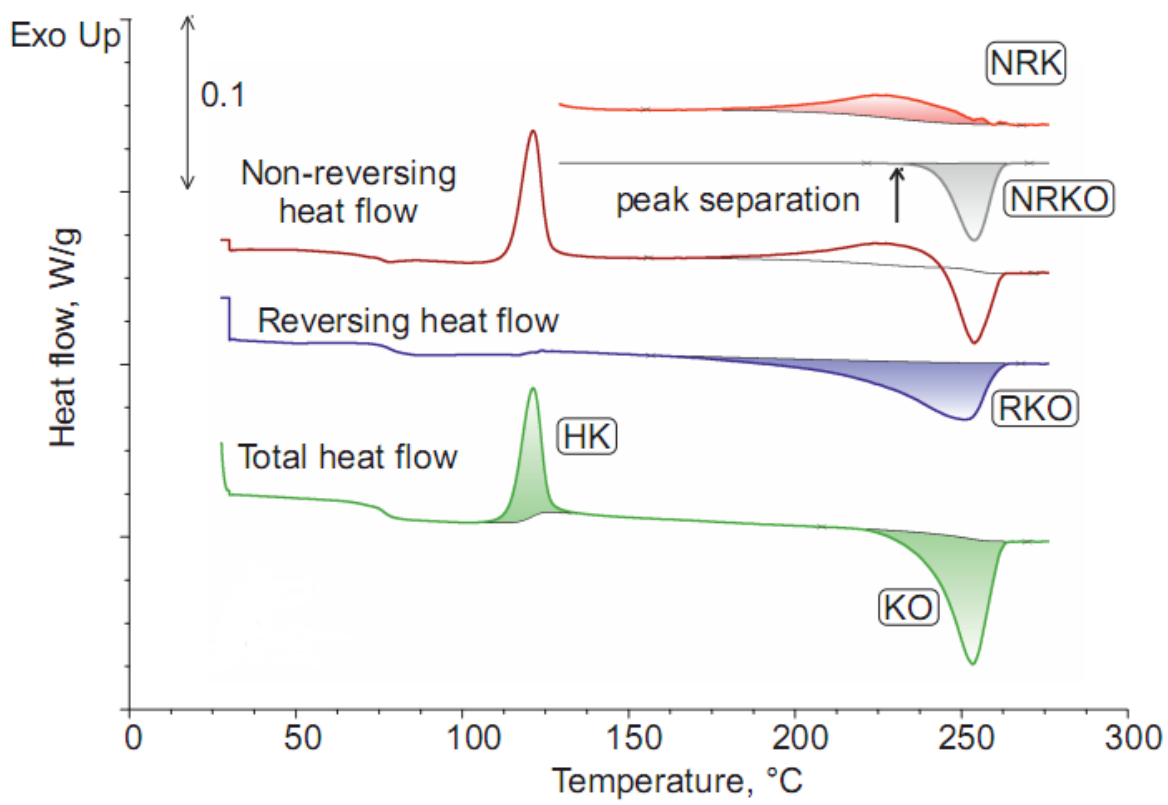

Figure 2. Calculated heat flow signals with investigated peaks (NRC: non-reversing crystallization, NRM: nonreversing melting, RM: reversing melting, CC: cold-crystallization, M: melting) 


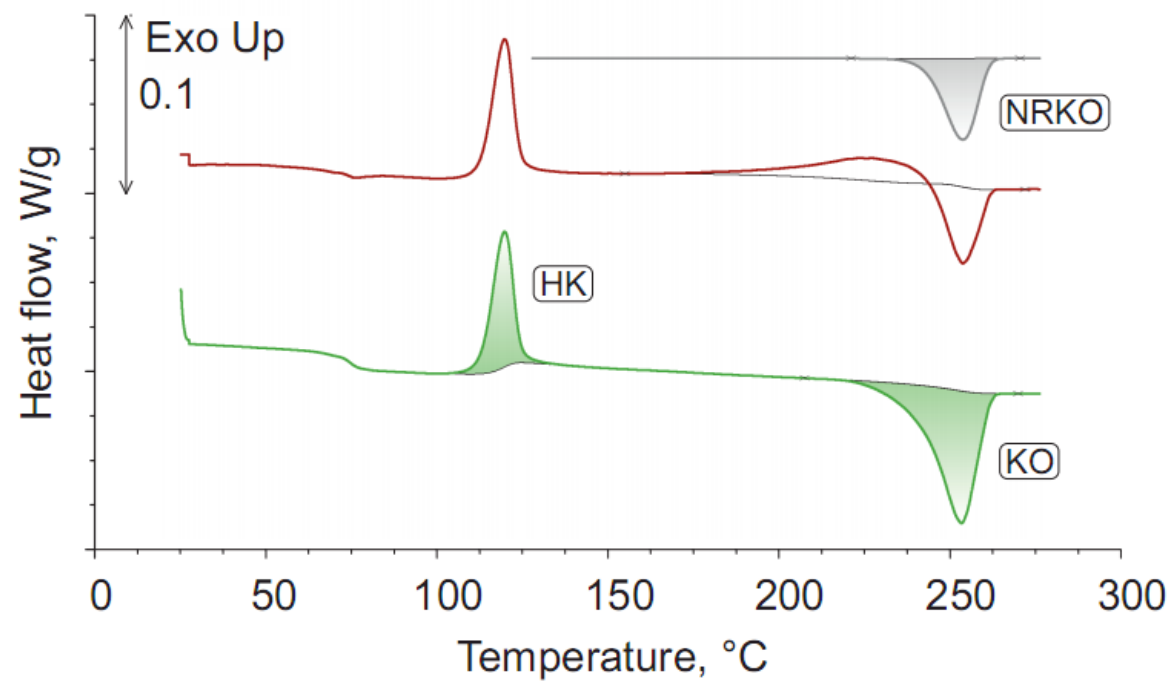

Figure 3. Initial crystallinity and non-reversing melting (NRM: non-reversing melting, CC: cold-crystallization, $\mathrm{M}$ : melting) 


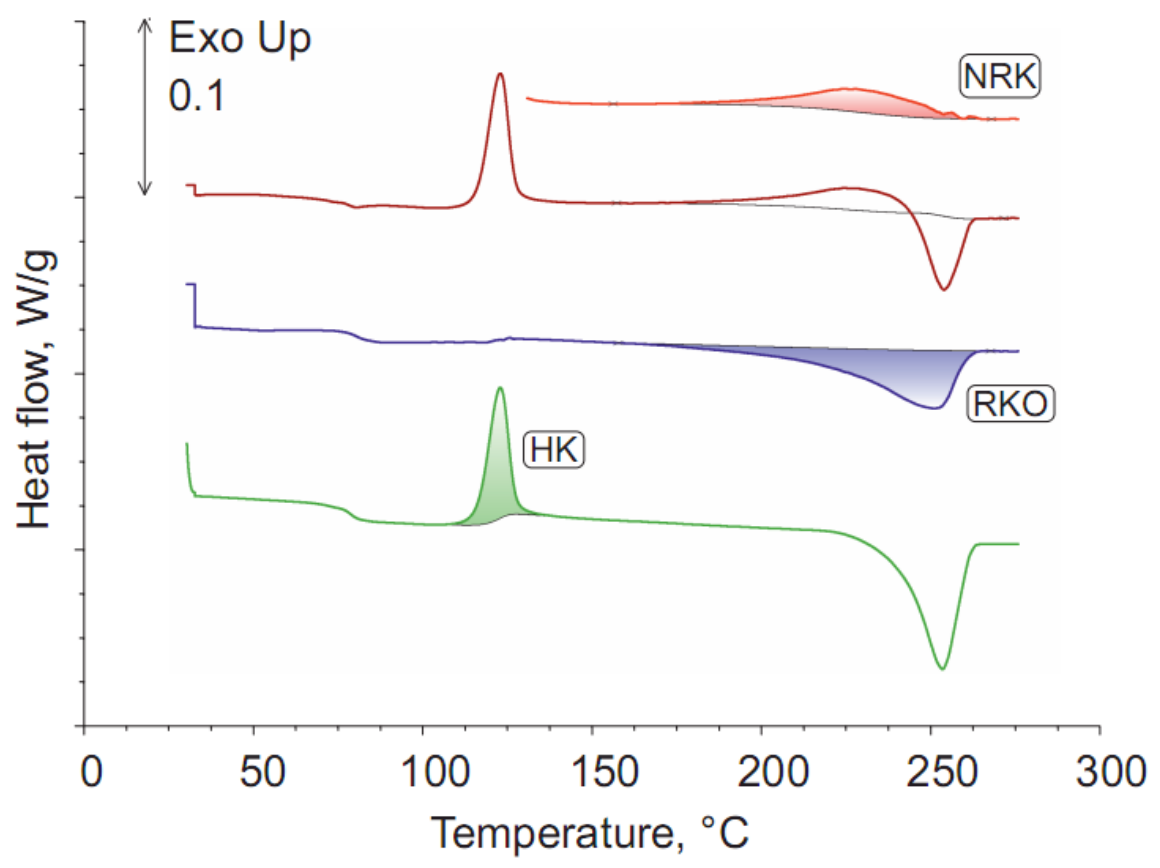

Figure 4. Post crystallization processes (cold- and non-reversing crystallization) and reversing melting (NRC: non-reversing crystallization, RM: reversing melting, CC: cold-crystallization) 